Article

\title{
The Role of Thermal Effects in Plasma Medical Applications: Biological and Calorimetric Analysis
}

\author{
Luigi Cordaro ${ }^{1,2, *}\left(\mathbb{D}\right.$, Gianluca De Masi ${ }^{1,3}{ }^{-0}$, Alessandro Fassina ${ }^{1}$, Clarice Gareri ${ }^{3}$, \\ Antonio Pimazzoni ${ }^{1,4}$, Daniele Desideri ${ }^{5}$, Ciro Indolfi ${ }^{3}$ and Emilio Martines ${ }^{1}$ (D) \\ 1 Consorzio RFX (CNR, ENEA, INFN, Università di Padova, Acciaierie Venete spa), Corso Stati Uniti 4, \\ 35127 Padova, Italy; gianluca.demasi@igi.cnr.it (G.D.M.); alessandro.fassina@igi.cnr.it (A.F.); \\ antonio.pimazzoni@igi.cnr.it (A.P.); emilio.martines@igi.cnr.it (E.M.) \\ 2 Centro Ricerche Fusione, University of Padova, Corso Stati Uniti 4, 35127 Padova, Italy; \\ 3 Division of Cardiology, Department of Medical and Surgical Sciences, Magna Graecia University of \\ Catanzaro, Viale Europa, 88100 Catanzaro, Italy; clarice88@hotmail.it (C.G.); indolfi@unicz.it (C.I.) \\ 4 INFN-LNL, Viale dell'Università 2, 35020 Legnaro, Italy \\ 5 Department of Industrial Engineering, University of Padova, Via Gradenigo 6/a, 35131 Padova, Italy; \\ daniele.desideri@unipd.it \\ * Correspondence: luigi.cordaro@igi.cnr.it
}

Received: 29 October 2019; Accepted: 11 December 2019; Published: 17 December 2019

\begin{abstract}
Plasma Medicine tools exploit the therapeutic effects of the exposure of living matter to plasma produced at atmospheric pressure. Since these plasmas are usually characterized by a non-thermal equilibrium (highly energetic electrons, low temperature ions), thermal effects on the substrate are usually considered negligible. Conversely, reactive oxygen and nitrogen species (RONS), UV radiation and metastables are thought to play a major role. In this contribution, we compare the presence of thermal effects in different operational regimes (corresponding to different power levels) of the Plasma Coagulation Controller (PCC), a plasma source specifically designed for accelerating blood coagulation. In particular, we analyze the application of PCC on human blood samples (in vitro) and male Wistar rats tissues (in vivo). Histological analysis points out, for the highest applied power regime, the onset of detrimental thermal effects such as red cell lysis in blood samples and tissues damages in in-vivo experiments. Calorimetric bench tests performed on metallic targets show that the current coupled by the plasma on the substrate induces most of measured thermal loads through a resistive coupling. Furthermore, the distance between the PCC nozzle and the target is found to strongly affect the total power.
\end{abstract}

Keywords: atmospheric pressure plasma jet (APPJ); cold atmospheric plasma (CAP); plasma medicine; blood coagulation; tissue damage

\section{Introduction}

The basic idea of plasma medicine is to create a therapeutic effect based on a chemical rather than a thermal interaction with the living substrate. To do that, plasma medicine tools, through different schemes [1,2], produce a cold plasma in which the ion branch is kept at room temperature and the temperature increase of the target due to the plasma action is rather small. Such a cold plasma produces, interacting with the air, reactive nitrogen and oxygen species (RONS) which, together with electrons, electric field, UV radiation and metastable species, are considered the main factors responsible for the therapeutic action on biological tissues [3-5]. The recognized applications, most studied so far in the field of plasma medicine, are the disinfection of bacteria and fungi and decontamination [4-10], dermatological diseases [11-14], surface treatment of materials and bio-materials [15-18], wounds healing [10,13,19-21], blood coagulation [22-24] and the selective killing of cancer cells [13,25-27]. 
In the Dielectric Barrier Discharge (DBD) scheme, the one used in the Plasma Coagulation Controller (PCC) $[23,28]$, plasma is usually produced by applying high voltage pulses at $\mathrm{kHz}$ frequencies between two close electrodes, separated by a dielectric layer. This last feature, together with the short duration (from hundreds ns to $1 \mu \mathrm{s}$ ) of the applied pulses, limits the amount of current flowing along the plasma to the target (and, of course, prevents the formation of an arc discharge). Indeed, reported measured currents on the target are usually of the order of few $\mathrm{mA}$ averaged over the entire duty cycle in a way that thermal effects are widely considered negligible.

However, even though a tentative standardization of the parameters within which plasma sources for bio-medical applications should operate has been proposed $[29,30]$, a certain degree of variability is still present in the plasma medicine arena in terms of applied power during the treatment and in its relative effect on the living substrate.

Although the thermal effects induced by biomedical cold plasmas are typically considered negligible, we believe they should be quantified and properly taken into consideration, to be sure of working under such conditions that the plasma has no unwanted consequences. The aim of this work is to focus on the main mechanisms that determine such thermal effects and whether they can be deleterious for application to living matter. In our case, the flexibility of PCC enables a fine tuning of the power coupled to the plasma, making possible an extensive characterization of the thermal component. As it will be shown throughout this paper, this feature makes PCC a suitable plasma source for clinical applications.

This contribution has two main goals-from one, side we analyze the effect of PCC on biological samples highlighting the presence of thermal effects in specific operational conditions (Section 2); on the other side, we estimate the power delivered by PCC through different bench tests on metallic targets (Section 3). The basic idea behind this analysis is, thus, to clarify in the different PCC operational regimes whether thermal effects take place in the plasma action and which roles they could have.

\section{The Effects of PCC on Biological Samples}

The Plasma Coagulation Controller (PCC), an innovative plasma medicine tool, has been designed to promote non-thermal blood coagulation in patients where normal coagulation cannot act properly or sufficiently fast.

In the PCC plasma source, rapid periodic high voltage pulses are applied to a main electrode covered by a pyrex capillary closed at the end. A gas (typically helium or argon), flowing through a nozzle, is ionized by the induced electric field and then expelled, resulting in a plasma plume which can be directly applied to a substrate.

The main features of PCC has been described elsewhere [28] as well as the preliminary results on blood samples [23].

In this analysis, we study the effect of the PCC treatment at different powers on two biological samples-Male Wistar Rats tissues (in vivo experiments, Section 2.1) and blood samples taken from patients following anti-coagulant therapy (in vitro experiments, Section 2.2). This is possible thanks to the high flexibility of PCC allowing the modulation of the power coupled on the substrate to be treated-applied voltage $\Delta V$ and discharge repetition rate $f$ can be easily varied through a graphic interface. For the sake of simplicity, in the following we compare three different operational regimes called, according to the applied power, LOW $(\Delta V=6 \mathrm{kV}, f=5 \mathrm{kHz})$, STD—standard $(\Delta V=8 \mathrm{kV}$, $f=5 \mathrm{kHz})$ and $\mathrm{HIGH}(\Delta V=8 \mathrm{kV}, f=10 \mathrm{kHz})$. In the following we will refer to these acronyms. It must be said that, under none of the mentioned conditions, excessive heat is felt when the plasma touches the fingers. 


\subsection{In Vivo Experiments}

\subsubsection{Methods}

Animal procedures have been performed conforming to the directive 2010/63/EU of the European Parliament and approved by the Italian Ministry of Health and by Institutional Animal Care and Use Committee of Magna Graecia University of Catanzaro, Italy. Male Wistar Rats, weighing 300-350 g, were randomly divided into four experimental groups - control (CTRL) that received no treatment, Low intensity (LOW), Standard intensity (STD) and High intensity (HIGH)-according to the PCC applied power. Rats from each experimental group have been anesthetized by intra-peritoneal injection of Zoletil (zolazepam hydrochloride and tiletamine hydrochloride; $20 \mathrm{mg} / \mathrm{kg}$ body weight) and Xylazine (10 mg/kg body weight). A slight cut was made at the femoral muscle level and the skin layer was removed. Right after, the PCC nozzle exit has been placed at $1 \mathrm{~cm}$ of distance from the muscle, and a single application at the relative intensity has been performed. The rats were euthanized by an overdose of Zoletil (100 mg/kg body weight) and Xylazine (10\%). Biopsies of femoral muscle of each experimental group have been withdrawn within 10' and embedded in paraffin; $5 \mu \mathrm{m}$ cross sections were prepared. Hematologist/Rosin (H/E) stainings were performed following the standard protocol.

\subsubsection{Results}

A rat model has been used to test the PCC potential side effects. After $90^{\prime \prime}$ of PCC treatment directly on the femoral muscle a biopsy has been taken and processed as described in the method section. Representative images are reported in Figure 1.
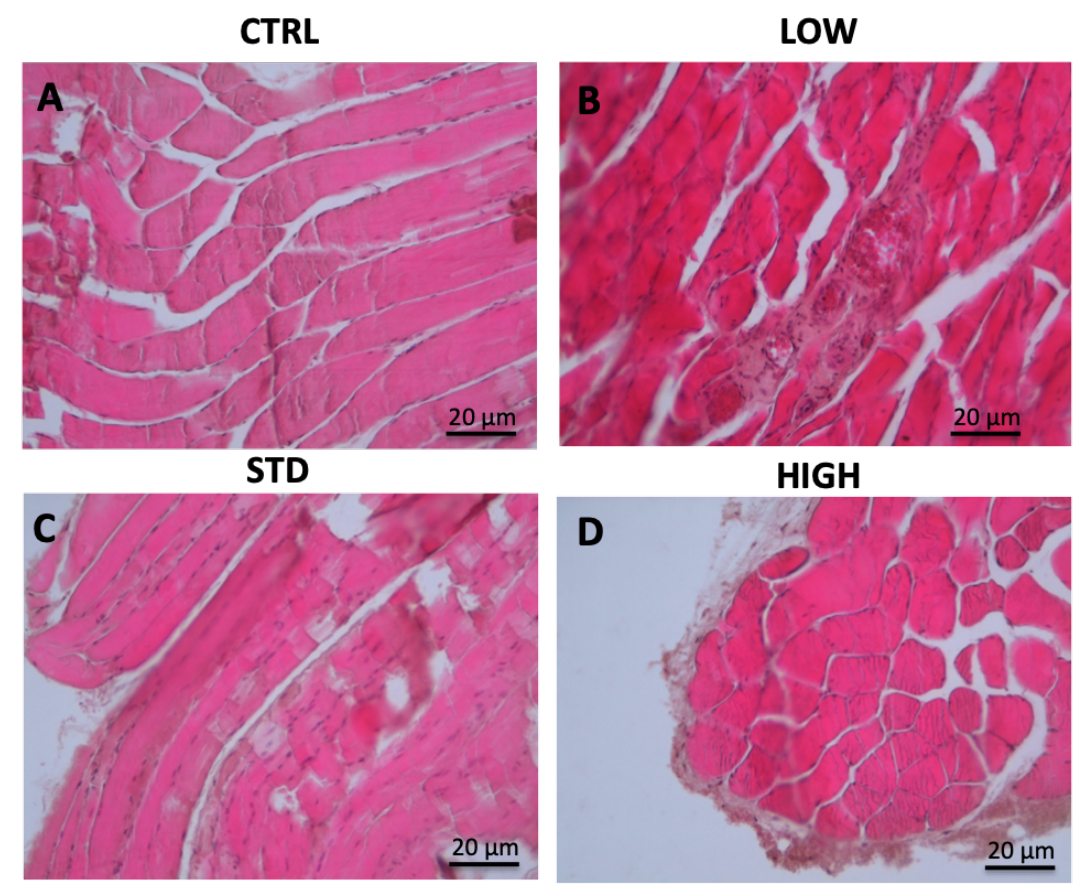

Figure 1. Plasma Coagulation Controller (PCC) effect on living tissue: representative images of $\mathrm{H} / \mathrm{E}$ staining on rat muscle after PCC treatment. (A) CTRL (no treatment). (B) 90" Low intensity treatment. (C) $90^{\prime \prime}$ STD intensity treatment. (D) $90^{\prime \prime}$ High intensity treatment.

As shown in Figure 1B, $90^{\prime \prime}$ of low intensity treatment does not affect the muscle fibers, which look mainly like the control (Figure 1A). On the contrary, few nematodes formations appear following $90^{\prime \prime}$ treatment at STD condition (Figure 1C); even if no major signs of damage, such as necrosis, are present. High intensity treatment has also been tested; in this case after $90^{\prime \prime}$ of treatment disruption of 
collagen fibers and dehydration of muscle fibers were beginning, suggesting that this action could be too aggressive for a potential use in the clinical practice (Figure 1D).

\subsection{In Vitro Experiments}

\subsubsection{Methods}

Blood samples have been withdrawn, after obtaining informed consent, from patients undergoing anti-coagulant therapy, enrolled in an on-going study registry at Magna Graecia University. A $50 \mu \mathrm{L}$ blood drop has been placed on the top part of a glass slide, placed at $1 \mathrm{~cm}$ from the tip of the PCC, treated for different time points following distinctive conditions (LOW, STD, HIGH) and a smear obtained. The sample was left to dry in the air for about $1 \mathrm{~h}$, fixed in formalin $\mathrm{o} / \mathrm{n}$ and Hematoxylin/Eosin (H/E) stainings have been performed following standard protocol.

\subsubsection{Results}

The histological analysis performed on blood smear after PCC treatment has showed both platelets aggregation and fibrin polymerization, indicating a pro-coagulant effect of the plasma source on the blood, even ex-vivo, with all the setting tested. Indeed, $60^{\prime \prime}$ at low intensity were sufficient to induce platelet aggregation and fibrin polymerization (Figure $2 \mathrm{~B}$ ) and the percentage of aggregation detected was proportional to the treatment intensity (Figure 2C,D). Despite the remarkable result observed for the blood coagulation, some concerning results appeared with the increase of intensity; after $60^{\prime \prime}$ at STD conditions, red cell lysis begins (Figure 2C) and rapidly increase with longer treatments (data not shown). Also, $60^{\prime \prime}$ of high intensity treatment cause a dramatic platelet aggregation and fibrin polymerization but also a robust red cell lysis. Of note, following longer treatments (more than $90^{\prime \prime}$ ) the samples volume was strongly reduced, suggesting that, as expected, the heat developed has the tendency to dry the sample and possibly play a role in the coagulation process. Moreover, high intensity treatment also display peculiar black colored spots at the platelet clot areas, possibly due to the accumulation of iron released by the red cells.

\section{CTRL}

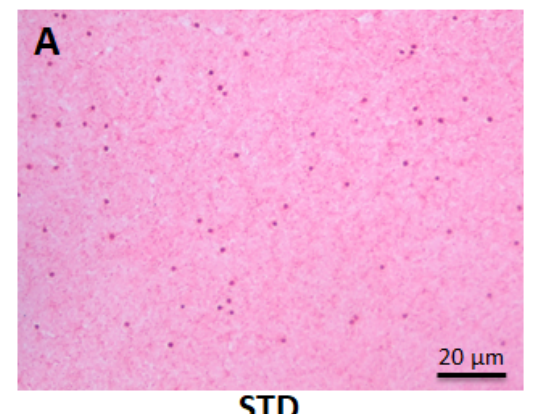

STD

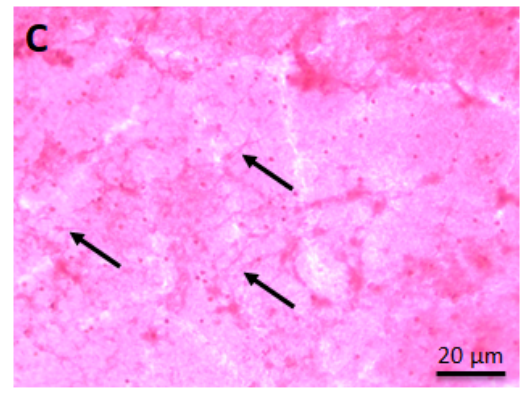

Low

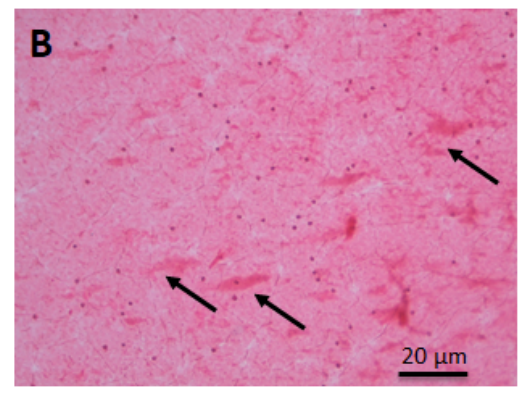

HIGH

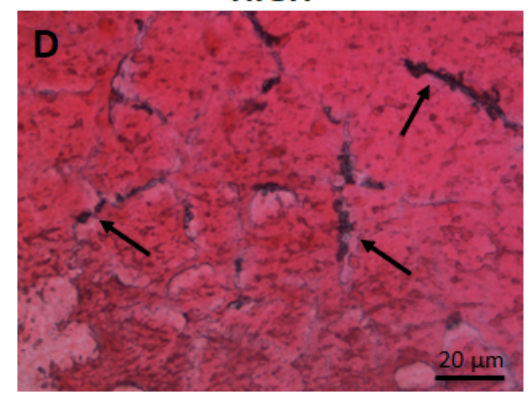

Figure 2. Blood Coagulation Analysis in vitro. Representative images of H/E staining on blood smears. (A) CTRL (no treatment). (B) $60^{\prime \prime} \mathrm{LOW}$ intensity treatment. (C) $60^{\prime \prime}$ STD intensity treatment. (D) $60^{\prime \prime}$ HIGH intensity treatment. The arrows indicate some platelet aggregates and fibrin networks. 


\subsection{Discussion}

One of the first steps in healing process is the hemostasis, which prevents the continuous bleeding through the clot formation. In this work, we demonstrated how PCC treatments can induce platelet aggregation and fibrin formation, suggesting that this tool might be extremely useful for accelerating clot formation and subsequent wound healing. This is not surprising, since it is known that reactive oxygen and nitrogen species induce platelet aggregation [31,32]. Recently, it has been shown that low temperature plasma tools, like PCC, are able to promote the clot formation by activating different pathways, which include not only the platelets but also red cells aggregation as well as inflammatory process driven by white cells. In our case, longer treatments displayed red cell lysis [33,34], according to Ikehara et al. 2013 [33], while at shorter time points the hemolysis was absent, indicating that in vitro shorter treatments resulted more efficacious. At the same time, direct PCC usage on the skeletal muscle has not shown deleterious effects, at least for short treatments.

Taken together these data show a direct effect of the plasma source on blood samples, as well as on muscle tissues. In both cases, the effect observed was proportional to the treatment time and intensity, even if the extent of the consequence was different in the two targets. Indeed, at the same condition, the substrate of living tissue showed a lower effect compared to the blood samples. These results are very promising for a possible use of the PCC in the clinical routine and, on the other side, point out the appearance of thermal effects in some operational conditions linked to the treatment duration, the applied power on the target and the electric features of the target itself.

\section{Calorimetric Measurements}

In order to assess the heat flux which may be coupled by plasma to a surface placed in front of the PCC, calorimetric measurements have been performed by means of an infra-red (IR) camera. Metallic targets were used since their thermal and electrical properties are known. In order to identify the key mechanism for the power deposition, targets of different materials and size were considered. In addition, the dependence of the delivered power from the target distance was investigated. Targets were either left floating or connected to ground.

\subsection{Experimental Setup}

A picture of the experimental setup is given in Figure 3. The PCC is horizontally oriented and the plasma plume is fed to the target, a thin metal foil placed vertically. The target distance from the PCC can be modified by means of a micrometric translation stage. The IR camera looks at the metal target from the opposite side with respect to the PCC head, hence the plasma is not seen directly.

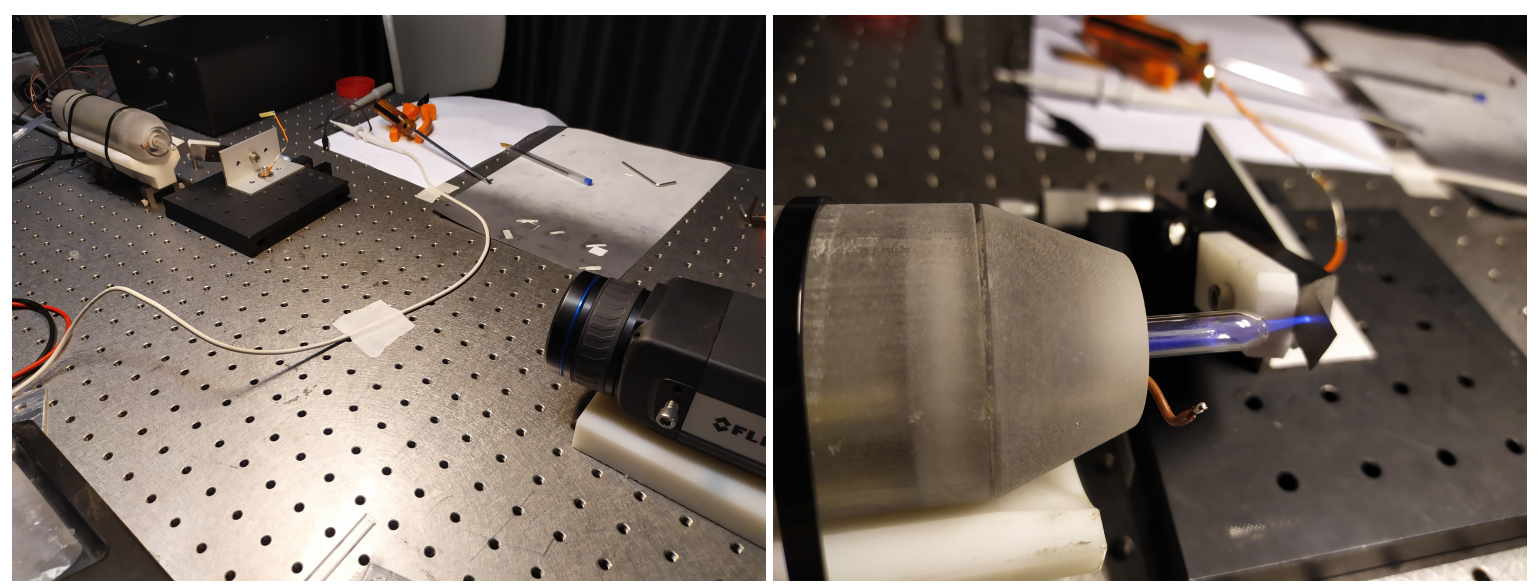

Figure 3. Experimental setup for calorimetric measurements. (Left) Plasma source and camera are placed on the opposite sides of the target. (Right) PCC plasma plume impinging on target. The distance between plasma source and substrate can be varied by means of a micrometer linear actuator. 
Dealing with a small average power (few Watts), thin foils (from 40 to $80 \mu \mathrm{m}$ ) were used, so to have a sufficiently small heat capacitance. In fact, considering the power level of the PCC, the temperature increase of thick sample would be quite small and thus affected by considerable errors. The adopted metal sheets, made of steel and brass, had dimensions of $12.7 \times 12.7 \mathrm{~mm}^{2}$ and $12.7 \times 5 \mathrm{~mm}^{2}$. To increase the thermal emissivity up to $\epsilon=0.8$, the surface observed by the IR camera was coated with a blackening layer (Molykote). The contribution of such a layer to the heat capacitance of the sample is considered negligible.

The IR camera (a FLIR A655sc) has a maximum sampling frequency of $f_{s}=50 \mathrm{~Hz}$ and a field of view of $15^{\circ} \times 11.25^{\circ}$ with a $640 \times 480$ pixel $^{2}$ sensor. The thermal power $P_{c a l}$ is estimated from the average temperature increase $\Delta T_{\text {avg }}$ of the target at $t=0.5 \mathrm{~s}$ after the plasma ignition as $P_{\text {cal }}=C \Delta T_{\text {avg }} / t$, where $C$ is the target heat capacitance. Such a short measurement interval was chosen to limit both the underestimation of $P_{c a l}$ due to the convective losses towards air and the error due to timing at $1 / f_{s} t$, that is $4 \%$.

Typical time traces of the target average temperature are shown in Figure 4.

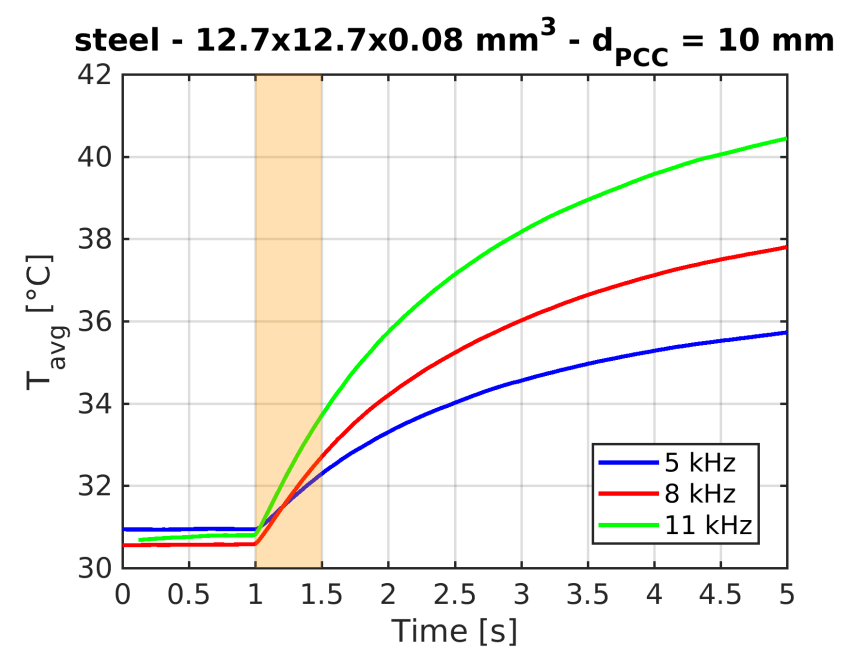

Figure 4. Time evolution of the average temperature of a stainless steel target $\left(12.7 \times 12.7 \times 0.08 \mathrm{~mm}^{3}\right)$ at a distance $d_{P C C}=10 \mathrm{~mm}$ from the source nozzle, at different working frequencies. The transparency area indicates the time interval in which the thermal power $P_{c a l}$ is estimated.

\subsection{Results}

As a first step, the expected dependence of $P_{c a l}$ from the operational frequency was verified (see Figure 5a) and a linear fit was found to be suitable. The calculated slope $A_{G R}$ for the grounded sample was found to be much larger (up to one order of magnitude) than the slope $A_{F L}$ calculated for the floating sample. This result suggests that the key mechanism for the power deposition to the sample is the current flow within the target itself. This hypothesis is confirmed by the dependence of $P_{\text {cal }}$ from the target thickness. In particular it was found that thicker samples have a significantly lower power deposition (see Figure 5b). Furthermore, for the same sample geometry, a smaller power (about 20\% less) was measured on brass samples than on steel samples (steel electrical resistivity is about $70 \%$ larger). 

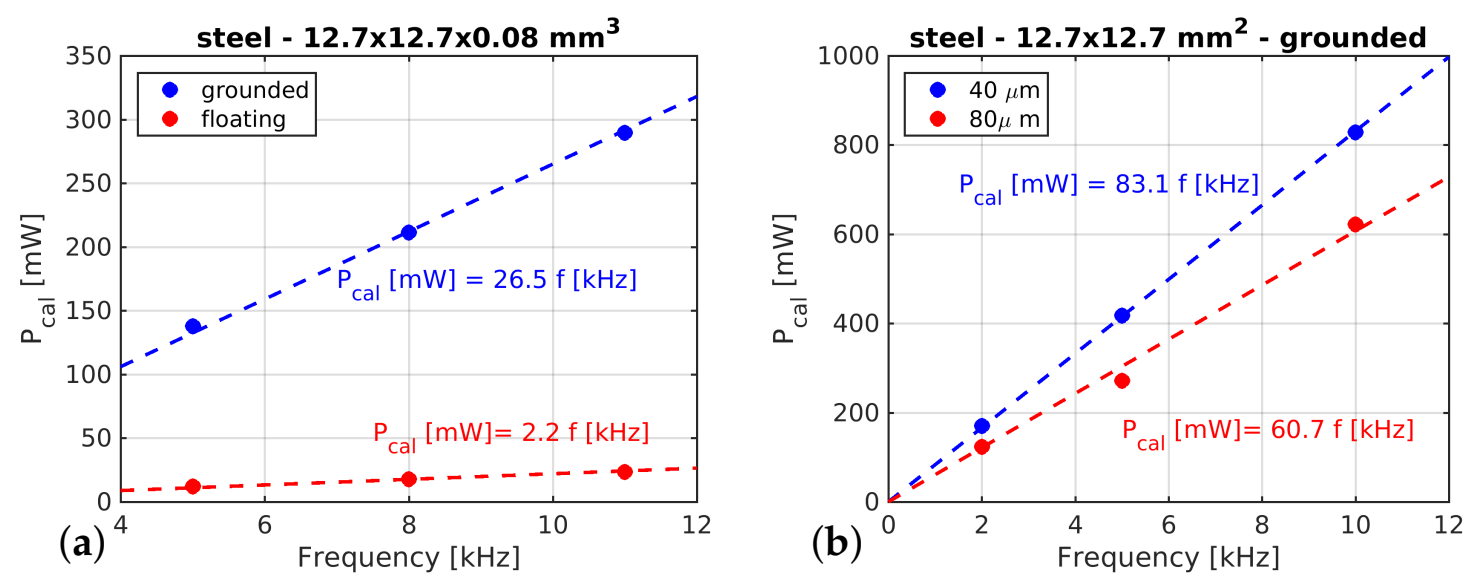

Figure 5. Calorimetric estimates of power at different frequency. (a) Comparison between grounded and floating samples. (b) Comparison between grounded samples of different thickness.

The dependence of $P_{c a l}$ on the target distance was found (for grounded samples) to be clear and monotonous as shown in Figure 6. In the first approximation, this is consistent with the lower interaction time between the plasma discharge (which propagates forward) and the substrate, as the distance source-substrate is increased. On the other hand, the plasma metal interaction region is strongly affected by the distance variation —-this implies a difference in the resistive coupling, since the current patterns cannot be considered constant.

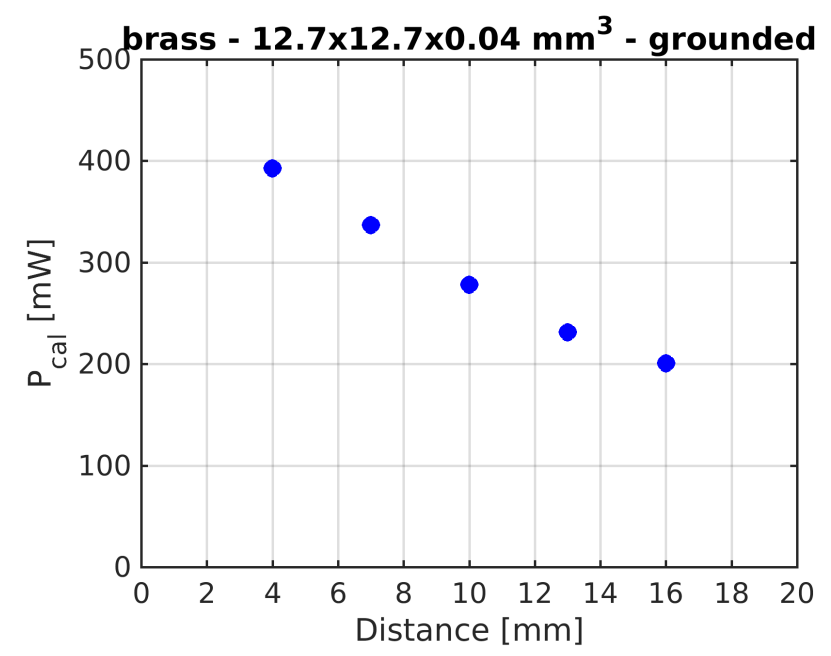

Figure 6. Calorimetric estimates of power at different distances from the PCC.

\subsection{Discussion}

The thermal power delivered by plasma has been determined, in several conditions of both power supply and distance, in different metallic foil samples. The performed analyses allowed to identify resistive coupling as the dominant mechanism for power deposition on the substrate. As a consequence, in order to precisely determine the heat load coupled upon a plasma treatment, it is necessary to infer the target resistivity. For this reason, extrapolating the load to biological samples is not trivial, since the substrate resistivity is not known and depends on the specific nature of the substrate. It could be useful, in this context, to use alternative materials, such as the soft gels described in Szili et al. (2014) [35], used as a model to simulate the transport of reactive species from plasma to biological tissues. However, even in that case, the thermal and electrical properties of such materials are almost unknown. So we preferred estimating the power carried by the plasma through the use of materials, of which we can precisely infer the chemical-physical properties. 
It must also be said that the estimated power values are comparable with those reported in Weltmann et al. (2009) [36]. In that work, as in ours, it is shown how the power decreases with the distance from the source. In addition, the importance of controlling the plasma dose was emphasized to avoid deleterious effects on living tissues. To our knowledge, there are not many publications showing the thermal output of the plasma, like the one we reported. However, the importance of avoiding overheating of the biological substrate is widely recognized to avoid cellular damage [37,38]. Among the latter, we can report the denaturation of proteins, evaporation of cellular liquid, structural alterations of the cell membrane, up to cell death $[37,39]$. The heat dose control is therefore fundamental for the clinical applications of cold plasmas. This control can be done in multiple ways-by varying the power coupled to the plasma, controlling the distance and the treatment time. In this context, PCC is a useful source of plasma for biomedical applications, thanks to its flexibility. We have shown that it is indeed possible to vary the power coupled to the plasma in such a way as to induce coagulation but avoiding, at the same time, the appearance of deleterious effects on biological tissues. Our calorimetric analysis therefore serves as a preliminary activity for tuning such a plasma dose. It must be said however that a direct thermographic measurement on the biological sample could be helpful to avoid undesired thermal loads. Furthermore, it shall be noticed that hand-held use of plasma sources would hardly grant a mm precision in the distance source-substrate, while mechanical suspension has to be preferred where possible (e.g., in vitro).

\section{Conclusions}

The effectiveness of cold plasmas in inducing a wide range of biological and therapeutic effects is demonstrated by a large and ever growing body of scientific literature. In most cases, it is generally assumed that thermal effects are negligible. This assumption is mostly based on the evaluation of the power deposition to the tissues performed through calorimetric measurements on targets of known material, typically metals. Also the existing international standards prescribe an evaluation of power transfer using copper targets of known features.

The objective of the present work was to evaluate the effectiveness of the PCC plasma source at different power levels, in relation to the task of inducing non-thermal blood coagulation. Our in vitro and in vivo tests showed that the plasma, at low power and for short time treatments, is indeed able to effectively accelerate platelet aggregation and fibrin formation, thus inducing coagulation. However, at higher powers and for longer treatments, also harmful effects appear, such as red cells lysis, with destruction of collagen fibers and dehydration of muscle fibers. It is worth mentioning that, in our case, higher powers and longer treatments have been applied only for characterization purposes, while are not necessary for obtaining therapeutic effects. On the other hand, this study demonstrates the importance of controlling the plasma dose for clinical applications, in order to avoid the appearance of tissue damage.

In carrying out this task, it was ascertained that the main heating mechanism is due to the electric current flowing in the sample. This leads to the conclusion that a power deposition evaluation performed on targets of given material could not be representative of what happens when the plasma is applied to actual living tissues. Indeed, the effect is expected to be remarkably different than in the case of metal targets. One might be tempted to prescribe the use of target materials which more closely resemble actual tissues in terms of resistivity, however also in this case a large uncertainty may be expected, due to the large variations of resistivity among different biological samples, especially when one includes conditions such as the presence of blood or other fluids. Furthermore, grounding of the treated sample is an issue which also affects power deposition.

Overall, these findings point to the necessity of having plasma sources where input power can be varied, as is the case for the PCC, so that it can be adjusted to the substrate conditions. Furthermore, being the thermal load and not the dissipated power the relevant quantity to be adjusted, one may envision, for the next generation of devices, methods to locally measure the substrate temperature and feedback systems to adjust power levels and/or distance between source and substrate so as to 
keep this quantity to a desired value [40]. The identification of the best technical solutions for the development of this new generation of tools will be the task for plasma physicists and engineers working in the plasma medicine field for the years to come.

Author Contributions: Conceptualization, L.C., G.D.M., A.F., C.G., A.P. and E.M.; Data curation, L.C., A.F., C.G. and A.P.; Formal analysis, C.G. and A.P.; Funding acquisition, G.D.M. and C.I.; Investigation, L.C., G.D.M., A.F., C.G., A.P. and D.D.; Project administration, G.D.M., C.I. and E.M.; Resources, D.D., C.I. and E.M.; Software, A.P.; Supervision, C.I. and E.M.; Validation, L.C., G.D.M., A.F., C.G., A.P., D.D. and E.M.; Visualization, L.C., A.F., C.G. and A.P.; Writing original draft, L.C., G.D.M., A.F., C.G. and A.P.; Writing review \& editing, L.C., G.D.M., A.F., C.G., A.P., D.D. and E.M.

Funding: This work was supported in part by the University of Padova-Department of Industrial Engineering, under Grant year 2017-BIRD171931 and in part by a research project named "A novel plasma medicine tool for accelerated haemostasis", which has received funding from the "Fondazione Con Il Sud" within the call "Brains2South".

Acknowledgments: The authors thank the Bionem Laboratory of the Department of Experimental and Clinical Medicine (University "Magna Graecia" of Catanzaro) for its technical support in the 3D printing activity of the PCC source; M. Maniero and M. Fincato for their valuable support during the experimental campaigns.

Conflicts of Interest: The authors declare no conflict of interest.

\section{References}

1. Weltmann, K.D.; Kindel, E.; von Woedtke, T.; Hähnel, M.; Stieber, M.; Brandenburg, R. Atmospheric-pressure plasma sources: Prospective tools for plasma medicine. Pure Appl. Chem. 2010, 82, 1223-1237. [CrossRef]

2. Von Woedtke, T.; Reuter, S.; Masur, K.; Weltmann, K.D. Plasmas for medicine. Phys. Rep. 2013, 530, $291-320$. [CrossRef]

3. Laroussi, M. Plasma medicine: A brief introduction. Plasma 2018, 1, 47-60. [CrossRef]

4. Kong, M.G.; Kroesen, G.; Morfill, G.; Nosenko, T.; Shimizu, T.; Van Dijk, J.; Zimmermann, J. Plasma medicine: An introductory review. New J. Phys. 2009, 11, 115012. [CrossRef]

5. Martines, E. Interaction of cold atmospheric plasmas with cell membranes in plasma medicine studies. Jpn. J. Appl. Phys. 2019, 59, SA0803, doi:10.7567/1347-4065/ab4860. [CrossRef]

6. Brun, P.; Pellizzaro, A.; Cavazzana, R.; Cordaro, L.; Zuin, M.; Martines, E. Mechanisms of Wound Healing and Disinfection in a Plasma Source for the Treatment of Corneal Infections. Plasma Med. 2017, 7, $147-157$. [CrossRef]

7. Martines, E.; Zuin, M.; Cavazzana, R.; Gazza, E.; Serianni, G.; Spagnolo, S.; Spolaore, M.; Leonardi, A.; Deligianni, V.; Brun, P.; et al. A novel plasma source for sterilization of living tissues. New J. Phys. 2009, 11, 115014, doi:10.1088/1367-2630/11/11/115014. [CrossRef]

8. O'Connor, N.; Cahill, O.; Daniels, S.; Galvin, S.; Humphreys, H. Cold atmospheric pressure plasma and decontamination. Can it contribute to preventing hospital-acquired infections? J. Hosp. Infect. 2014, 88, 59-65, doi:10.1016/j.jhin.2014.06.015. [CrossRef]

9. Hertwig, C.; Meneses, N.; Mathys, A. Cold atmospheric pressure plasma and low energy electron beam as alternative nonthermal decontamination technologies for dry food surfaces: A review. Trends Food Sci. Technol. 2018, 77, 131-142, doi:10.1016/j.tifs.2018.05.011. [CrossRef]

10. Brehmer, F.; Haenssle, H.; Daeschlein, G.; Ahmed, R.; Pfeiffer, S.; Görlitz, A.; Simon, D.; Schön, M.; Wandke, D.; Emmert, S. Alleviation of chronic venous leg ulcers with a hand-held dielectric barrier discharge plasma generator (PlasmaDerm ${ }^{\circledR}$ VU-2010): Results of a monocentric, two-armed, open, prospective, randomized and controlled trial (NCT 01415622). J. Eur. Acad. Dermatol. Venereol. 2015, 29, 148-155. [CrossRef]

11. Metelmann, H.R.; Vu, T.T.; Do, H.T.; Le, T.N.B.; Hoang, T.H.A.; Phi, T.T.T.; Luong, T.M.L.; Nguyen, T.T.H.; Nguyen, T.H.M.; Nguyen, T.L.; et al. Scar formation of laser skin lesions after cold atmospheric pressure plasma (CAP) treatment: A clinical long term observation. Clin. Plasma Med. 2013, 1, 30-35. [CrossRef]

12. Emmert, S.; Brehmer, F.; Hänßle, H.; Helmke, A.; Mertens, N.; Ahmed, R.; Simon, D.; Wandke, D.; Maus-Friedrichs, W.; Däschlein, G.; et al. Atmospheric pressure plasma in dermatology: Ulcus treatment and much more. Clin. Plasma Med. 2013, 1, 24-29. [CrossRef] 
13. Bernhardt, T.; Semmler, M.L.; Schäfer, M.; Bekeschus, S.; Emmert, S.; Boeckmann, L. Plasma Medicine: Applications of Cold Atmospheric Pressure Plasma in Dermatology. Oxidative Med. Cell. Longev. 2019, 2019, 3873928. [CrossRef] [PubMed]

14. Chutsirimongkol, C.; Boonyawan, D.; Polnikorn, N.; Techawatthanawisan, W.; Kundilokchai, T. Non-Thermal Plasma for Acne and Aesthetic Skin Improvement. Plasma Med. 2014, 4, 79-88. [CrossRef]

15. Stoffels, E.; Flikweert, A.J.; Stoffels, W.W.; Kroesen, G.M.W. Plasma needle: A non-destructive atmospheric plasma source for fine surface treatment of (bio)materials. Plasma Sources Sci. Technol. 2002, 11, 383-388, doi:10.1088/0963-0252/11/4/304. [CrossRef]

16. Malinowski, S.; Herbert, P.A.F.; Rogalski, J.; Jaroszyńska-Wolińska, J. Laccase Enzyme Polymerization by Soft Plasma Jet for Durable Bioactive Coatings. Polymers 2018, 10, 532, doi:10.3390/polym10050532. [CrossRef] [PubMed]

17. Malinowski, S.; Wardak, C.; Jaroszyńska-Wolińska, J.; Herbert, P.A.F.; Panek, R. Cold Plasma as an Innovative Construction Method of Voltammetric Biosensor Based on Laccase. Sensors 2018, 18, 4086, doi:10.3390/s18124086. [CrossRef]

18. Malinowski, S.; Jaroszyńska-Wolińska, J.; Herbert, P.A.F. Theoretical insight into plasma deposition of laccase bio-coating formation. J. Mater. Sci. 2019, 54, 10746-10763, doi:10.1007/s10853-019-03641-2. [CrossRef]

19. Fridman, G.; Friedman, G.; Gutsol, A.; Shekhter, A.B.; Vasilets, V.N.; Fridman, A. Applied Plasma Medicine. Plasma Process. Polym. 2008, 5, 503-533. [CrossRef]

20. Haertel, B.; Von Woedtke, T.; Weltmann, K.D.; Lindequist, U. Non-thermal atmospheric-pressure plasma possible application in wound healing. Biomol. Ther. 2014, 22, 477. [CrossRef]

21. Schmidt, A.; Bekeschus, S.; Wende, K.; Vollmar, B.; von Woedtke, T. A cold plasma jet accelerates wound healing in a murine model of full-thickness skin wounds. Exp. Dermatol. 2017, 26, 156-162. [CrossRef] [PubMed]

22. Ikehara, S.; Sakakita, H.; Ishikawa, K.; Akimoto, Y.; Yamaguchi, T.; Yamagishi, M.; Kim, J.; Ueda, M.; Ikeda, J.I.; Nakanishi, H.; et al. Plasma blood coagulation without involving the activation of platelets and coagulation factors. Plasma Process. Polym. 2015, 12, 1348-1353. [CrossRef]

23. De Masi, G.; Gareri, C.; Cordaro, L.; Fassina, A.; Brun, P.; Zaniol, B.; Cavazzana, R.; Martines, E.; Zuin, M.; Marinaro, G.; et al. Plasma Coagulation Controller: A Low- Power Atmospheric Plasma Source for Accelerated Blood Coagulation. Plasma Med. 2018, 8, 245-254. [CrossRef]

24. Fridman, G.; Peddinghaus, M.; Balasubramanian, M.; Ayan, H.; Fridman, A.; Gutsol, A.; Brooks, A. Blood Coagulation and Living Tissue Sterilization by Floating-Electrode Dielectric Barrier Discharge in Air. Plasma Chem. Plasma Process. 2006, 26, 425-442. [CrossRef]

25. Martines, E.; Brun, P.; Artico, R.; Cavazzana, R.; Cordaro, L.; Fischetto, D.; Zuin, A.; Zuin, M. Intracellular Rons Increase Induced By Helium Plasma Triggers Apoptosis In Cancer Cells. Clin. Plasma Med. 2018, 9, 28-29. [CrossRef]

26. Keidar, M.; Shashurin, A.; Volotskova, O.; Ann Stepp, M.; Srinivasan, P.; Sandler, A.; Trink, B. Cold atmospheric plasma in cancer therapy. Phys. Plasmas 2013, 20, 057101. [CrossRef]

27. Metelmann, H.R.; Seebauer, C.; Rutkowski, R.; Schuster, M.; Bekeschus, S.; Metelmann, P. Treating cancer with cold physical plasma: On the way to evidence-based medicine. Contrib. Plasma Phys. 2018, 58, 415-419. [CrossRef]

28. Cordaro, L.; De Masi, G.; Fassina, A.; Mancini, D.; Cavazzana, R.; Desideri, D.; Sonato, P.; Zuin, M.; Zaniol, B.; Martines, E. On the Electrical and Optical Features of the Plasma Coagulation Controller Low Temperature Atmospheric Plasma Jet. Plasma 2019, 2, 156-167. [CrossRef]

29. International Electrotechnical Commission. IEC 60601-2-76:2018 Medical Electrical Equipment-Part 2-76: Particular Requirements for the Basic Safety and Essential Performance of Low Energy Ionized Gas Haemostasis Equipment; International Electrotechnical Commission: Geneva, Switzerland, 2018.

30. Mann, M.S.; Tiede, R.; Gavenis, K.; Daeschlein, G.; Bussiahn, R.; Weltmann, K.D.; Emmert, S.; von Woedtke, T.; Ahmed, R. Introduction to DIN-specification 91315 based on the characterization of the plasma jet kINPen ${ }^{\circledR}$ MED. Clin. Plasma Med. 2016, 4, 35-45. [CrossRef]

31. Pignatelli, P.; Pulcinelli, F.M.; Lenti, L.; Gazzaniga, P.P.; Violi, F. Hydrogen peroxide is involved in collagen-induced platelet activation. Blood 1998, 91, 484-490. [CrossRef]

32. Bekeschus, S.; Schmidt, A.; Weltmann, K.D.; von Woedtke, T. The plasma jet kINPen-A powerful tool for wound healing. Clin. Plasma Med. 2016, 4, 19-28. [CrossRef] 
33. Ikehara, Y.; Sakakita, H.; Shimizu, N.; Ikehara, S.; Nakanishi, H. Formation of membrane-like structures in clotted blood by mild plasma treatment during hemostasis. J. Photopolym. Sci. Technol. 2013, 26, 555-557. [CrossRef]

34. Miyamoto, K.; Ikehara, S.; Takei, H.; Akimoto, Y.; Sakakita, H.; Ishikawa, K.; Ueda, M.; Ikeda, J.I.; Yamagishi, M.; Kim, J.; et al. Red blood cell coagulation induced by low-temperature plasma treatment. Arch. Biochem. Biophys. 2016, 605, 95-101. [CrossRef] [PubMed]

35. Szili, E.J.; Bradley, J.W.; Short, R.D. A 'tissue model'to study the plasma delivery of reactive oxygen species. J. Phys. Appl. Phys. 2014, 47, 152002. [CrossRef]

36. Weltmann, K.D.; Kindel, E.; Brandenburg, R.; Meyer, C.; Bussiahn, R.; Wilke, C.; Von Woedtke, T. Atmospheric pressure plasma jet for medical therapy: Plasma parameters and risk estimation. Contrib. Plasma Phys. 2009, 49, 631-640. [CrossRef]

37. Zenker, M. Argon plasma coagulation. GMS Krankenhaushygiene Interdiszip. 2008, 3.

38. Keidar, M.; Walk, R.; Shashurin, A.; Srinivasan, P.; Sandler, A.; Dasgupta, S.; Ravi, R.; Guerrero-Preston, R.; Trink, B. Cold plasma selectivity and the possibility of a paradigm shift in cancer therapy. Br. J. Cancer 2011, 105, 1295. [CrossRef]

39. Kalghatgi, S.U.; Fridman, G.; Fridman, A.; Friedman, G.; Clyne, A.M. Non-thermal dielectric barrier discharge plasma treatment of endothelial cells. In Proceedings of the 2008 30th Annual International Conference of the IEEE Engineering in Medicine and Biology Society, Vancouver BC, Canada,20-25 Aug. 2008; pp. 3578-3581.

40. Gidon, D.; Graves, D.B.; Mesbah, A. Predictive control of 2D spatial thermal dose delivery in atmospheric pressure plasma jets. Plasma Sources Sci. Technol. 2019, 28, 085001. [CrossRef]

(C) 2019 by the authors. Licensee MDPI, Basel, Switzerland. This article is an open access article distributed under the terms and conditions of the Creative Commons Attribution (CC BY) license (http:/ / creativecommons.org/licenses/by/4.0/). 